\title{
De uma crítica e seus destinos
}

\author{
The afterlives of an essay
}

\section{Ana Bigotte Vieira}

Ana Bigotte Vieira

Doutora em Ciências da Comunicação/ Cultura

Contemporânea - Arte e Comunicação pela Universidade Nova

de Lisboa. Historiadora, dramaturgista em teatro e em dança.

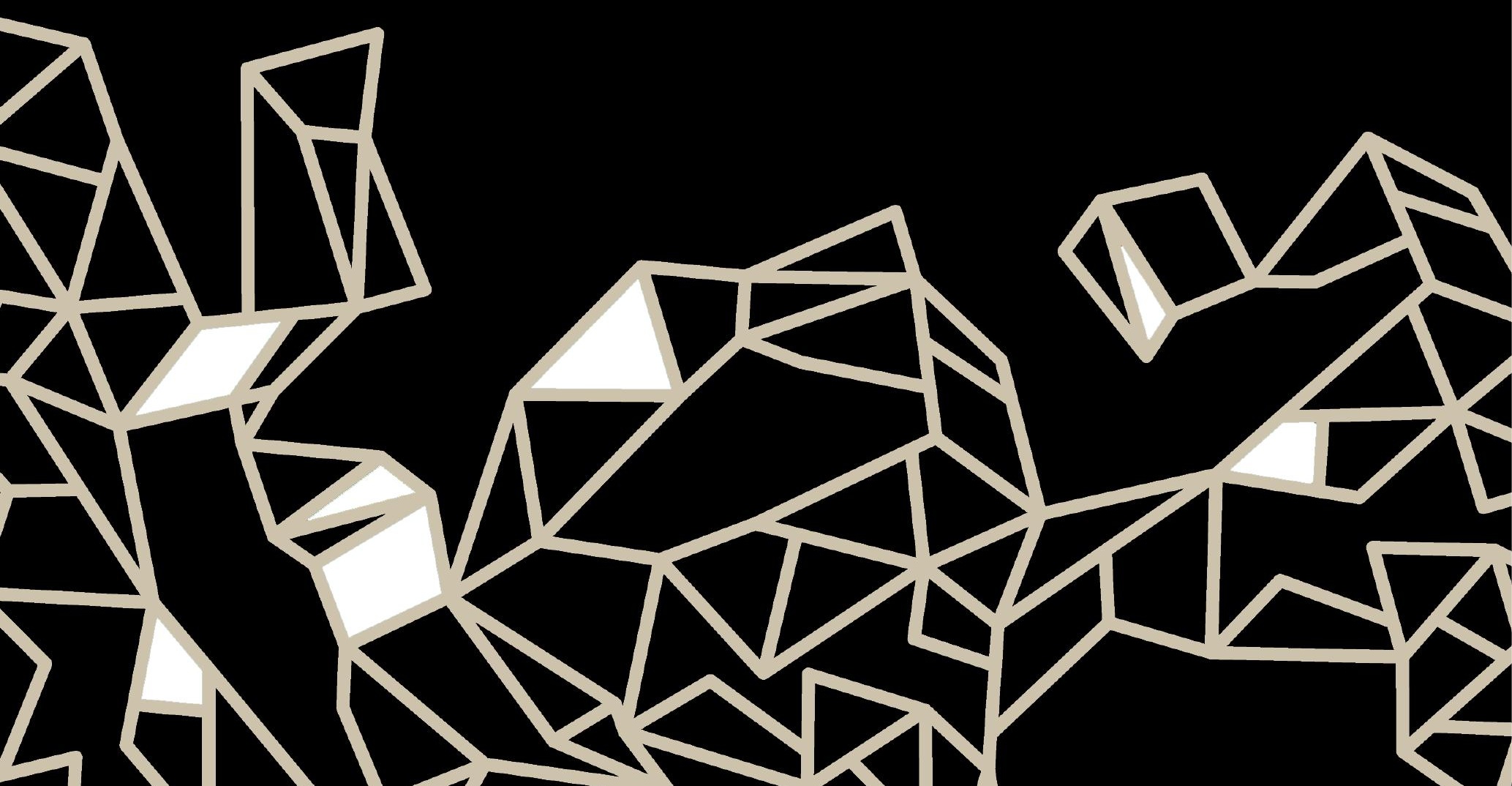




\section{Resumo}

Revisitando um texto escrito no âmbito de uma apresentação sobre "Trabalho nas artes e na ciência" a convite da plataforma de teoria crítica Unipop, e tendo como ponto de partida o espectáculo Han Shot First, de Diogo Bento e Inês Vaz, discute-se "Exaustão" e "Celebração" como tonalidades emotivas paradigmáticas daquilo a que Bojana Kunst chama "temporalidade projectiva", um tipo de temporalidade ligada à contínua interpelação para que se façam projectos que caracterizem o trabalho nas artes e na ciência hoje em dia.

Palavras-chave: Projecto, Precariedade, Exaustão, Celebração, Teatro, Tonalidades afectivas (Stimmung).

\section{Abstract}

Revisiting an essay on "working conditions in the arts and academia" written at the invitation of the critical theory platform Unipop, the author discusses the concepts of "Exhaustion" and "Celebration" as affective tonalities of what Bojana Kunst calls "projective temporality", a sort of temporality connected to the continuous demand for projects that characterize work in arts and academia nowadays. This reflection has at starting point the performance Han shot first, by Diogo Bento and Inês Vaz, presented in Lisbon in 2010.

Keywords: Project, Precariousness, Exhaustion, Celebration, Theatre, Stimmung.

Em 2014, a plataforma Unipop ${ }^{1}$ e a Revista Imprópria convidaram-me para participar de um seminário intitulado "Pensamento Crítico Contemporâneo e Trabalho", que teria lugar no Instituto Inter-Universitário de Lisboa (ISCTE-IUL) em outubro daquele ano. Propunham-me que abordasse o tema

1 Para categorização do que é a Unipop, recorre-se aqui a um excerto de um texto apresentado pelo colectivo na Commoniversity 2010, encontro europeu de universidades anómalas realizado em Barcelona, de 25 a 27 de novembro de 2007: "Unipop is a Lisbon collective set up in 2007 to disseminate critical theory and militant practice beyond the narrow confines of the academic circuit, and to open up spaces where contemporary capitalism can be subject to analysis and political intervention. Unipop has a few core members but operates as a network that over the past few years has relied on the participation of hundreds of individual militants and academics as well as a number of independent organizations" (UNIPOP, 2011). 
"Trabalho nas Artes e na Ciência", integrando com isso o painel "Trabalho e Antitrabalho". A ideia seria que a minha apresentação incidisse sobre precariedade e regimes de intermitência na arte e na ciência, tema, à época, bastante menos popularizado no país do que hoje em dia. ${ }^{2}$

Ainda em 2014, a mais de um mês de distância da apresentação, aceitei a proposta, que me pareceu mais do que necessária, e propus falar "sobre fazer projectos e a temporalidade que isso implica: performance, eficácia resistência e desgaste" (VIEIRA, 2014) - enunciando, assim, ainda que inadvertidamente, aquele que acabaria por vir a ser o título da apresentação.

Apresentação feita, uns meses mais tarde o texto da apresentação que se constitui tendo como centro temático o espectáculo Han Shot First, de Diogo Bento e Inês Vaz ${ }^{3}$ - viria a ser publicado na plataforma de teoria crítica online Punkto.

Revisitando e repropondo na revista Sala Preta o texto então escrito, gostava de abri-lo à problematização, para que se interrogue, por um lado, o modo como ocasionalmente certos espectáculos, como Han Shot First, se constituem enquanto momentos privilegiados de articulação de pensamento crítico, erigindo-se como formas afectivas e sensoriais de dar a ver tensões e cinéticas que perpassam o quotidiano actual, desobscurecendo o performativo dos gestos que fazemos quotidianamente; e, por outro, um duplo desalinhamento

2 No programa completo da jornada podia-se ler: "Seminário Pensamento Crítico Contemporâneo e Trabalho [...] Historicamente, o trabalho tem constituído um elemento central da crítica aos mais variados sistemas de dominação económica e social. Do esclavagismo ao capitalismo, passando pela experiência do socialismo real, o trabalho tem sido analisado como a fonte e o motor de acumulação destes regimes e, ao mesmo tempo, como o seu coveiro. Nas últimas décadas, o trabalho tem sofrido um conjunto de mudanças significativas. A mudança nas formas de organização empresarial, a crise do movimento operário, a precariedade contratual e o próprio tipo de trabalho realizado, alimentado por um conjunto de elementos humanos que não só o corpo (a emoção, a imaginação, a criatividade) vieram colocar em causa o próprio conceito de trabalho. A propagação de conceitos como o de "empreendedor", ou mesmo de "empresário", constitui tentativas de aprofundamento deste processo. À luz do pensamento de teóricos como Karl Marx e Hannah Arendt, mas igualmente de autores contemporâneos como Robert Kurz, Moishe Postone, André Gorz ou Saskia Sassen, pretendemos identificar os pontos em comum entre o trabalho realizado pelo velho operário fordista, o serviço executado pela empregada doméstica e a actividade desempenhada pelo designer gráfico. Mais do que uma análise sociológica em torno destas mudanças, a Unipop e a Associação de Estudantes do ISCTE-IUL propõem uma reflexão crítica que, sem negar o alcance do trabalho na vida de cada um, consiga apontar uma existência emancipada para lá deste" (UNIPOP, 2014).

3 Han Shot First foi apresentado no Teatro Taborda em 2010, no âmbito do ciclo Try Better, Faill Better. 
que, a posteriori, percebi atravessar texto e contexto da proposta, que foi, ainda assim, extremamente bem recebida.

É que não apenas - não obstante o seu referencial seja um espectáculo de teatro - este tipo de análise não participa do que habitualmente em Portugal é tido como a reflexão possível sobre artes performativas (não tem espaço na imprensa nem no mercado editorial, nem este tipo de olhar, de análise crítica sobre objectos culturais, é incentivado nas escolas), mas também, e justamente por isso mesmo (por ter como referente um espectáculo), ela se encontra igualmente deslocada do que costuma ser o objecto de debate de plataformas de pensamento crítico como a Unipop ou mesmo a Punkto, no interior dos quais foi pensada e acolhida. Ou seja, se a proposta - não se focando particularmente na obra, no percurso dos criadores ou no processo de trabalho - parecia não encontrar espaço nos circuitos tradicionais reservados às artes performativas, ao ter como ponto de partida e ao procurar pensar com e através de um espectáculo, ela também não encaixava exactamente nos circuitos locais de teoria crítica, onde raramente espectáculos são tematizados, muito menos como matéria ou ferramentas com que $(m)$ pensar.

Em causa parecia estar não só uma atenção à posição discursiva do espectáculo (o que diz, como o que diz se inscreve na trama dos discursos existentes - já de si um alargamento diante da obsessão da crítica tradicional pelo "percurso do criador" e a "excelência da obra"), mas uma especial atenção aos modos como a obra faz o que faz, constituindo nesse fazer, nos seus modos particulares, a referida posição discursiva e alargando por eles e com eles os próprios contornos da produção de discurso (não apenas escrito, não apenas racional, não apenas certo, não apenas legitimado).

E em causa também o ímpeto de contribuir para que se comece a interrogar os lugares onde se treina e se exercita um olhar sobre o performativo das práticas e os preceitos ético-estéticos que Ihes subjazem, pois tal ajudaria, quiçá, a compreender melhor uma série de práticas e comportamentos sociais, para além de permitir uma leitura estética mais apurada das artes performativas em geral.

Necessário seria igualmente interrogar a fundo tipologias de espaço onde a escrita crítica sobre artes performativas e o performativo das práticas 
tem ou pode ter lugar (e sob que condições) e o lugar que o fazer e escrever criticamente sobre espectáculos neles assume.

Mas apresente-se primeiro o referido texto:

\section{Abertura}

Há qualquer coisa, mais uma sensação do que um discurso bem articulado, neste trailer de Han Shot First ${ }^{4}$ (clique no player ao lado), que gostava de convocar. Espectáculo arranque - de e sobre o início, sobre a dificuldade do início, este foi o começo da colaboração de Diogo Bento e Inês Vaz. Atente-se aos primeiros minutos do referido trailer.

Paremos, aqui, aos um minuto e onze segundos, e fiquemos então com as frases "sempre nós os dois - e mais um bocadinho; nós os dois - e mais um bocadinho", mas, sobretudo, "O que não é muito interessante, bem sabemos, mas é aquilo que temos À MÃO".

\section{Sobre fazer projectos e a temporalidade que isso im- plica: eficácia, performance, resistência e desgaste}

Avancei com este título muito antes de ter escrito o texto que aqui leio e, assim, de certa forma, ele passou a funcionar como o projecto da minha apresentação. E um projecto funciona como uma promessa.

Em The Project Horizon: On the Temporality of Making, Bojana Kunst (2012) parte da proliferação da palavra "projecto" - estamos todos envolvidos em diversos projectos, por vezes mais do que um ao mesmo tempo, em diferentes latitudes, e muitas vezes quando iniciamos o seguinte não terminamos ainda o anterior - para traçar uma análise daquilo a que chamou uma "temporalidade de projecto".

Em sua opinião, o termo denotaria então um modo temporal, uma atitude projectiva em que se navegaria entre vários projectos (realizados, em curso e não realizados ainda) procurando descortinar um futuro por entre eles alinhavado.

No entanto, e se a imaginação do futuro tem sido terreno para experimentações artísticas colaborativas várias - e pense em como frequentemente

4 Disponível em: <https://www.youtube.com/watch?v=tgJ0RbFnljo>. 
os processos de trabalho colaborativo, por exemplo, nas artes performativas, contêm em si uma proposta de utopia a realizar ali, durante o tempo do ensaio, durante o tempo que antecede a finalização do projecto ${ }^{5}-$, a temporalidade a que Kunst alude, essa temporalidade de projecto, força essa mesma imaginação do futuro a depender de circunstâncias e modos de produção que Ihe são totalmente alheios, impossibilitando-a quase de supor e criar modos de vida política e económica diferentes dos existentes. Conhecemo-lo bem: chamamos-lhes candidaturas, concursos, pitching, fundraising. São os momentos de apresentação do projecto, do lacrar da candidatura, da submissão da proposta e do conhecimento dos resultados. São os procedimentos que visam tornar materialmente exequível o que se projectou, reunir as condições de possibilidade para que o projecto realmente aconteça.

Pontuando a sua análise com exemplos concretos de performances em que essas questões são afectivamente trazidas à boca de cena (Kunst analisa Product of Other Circumstances, de Xavier Le Roy, e Fate Work, de Stefano Harney e Valentina Desideri), a autora afirma que o "projecto", palavra usada para nomear uma multiplicidade de trabalhos singulares que se dão a ver (e a fazer) enquanto infinita e contínua adição de suplementos discretos - e relembro aqui o "tudo isto e mais um bocadinho" do espectáculo de Diogo Bento e Inês Vaz, que ouvimos há pouco - se transformou no horizonte último do fazer actual.

Mas nessa temporalidade contínua, após a finalização de um projecto, é sempre necessário recomeçar de novo pelo que, independentemente das possibilidades abertas, há uma temporalidade que à partida se encontra cerceada pelo seu próprio terminar, i.e, por um lado, pela realização de algo já anteriormente projectado ${ }^{6} \mathrm{e}$, por outro, pelo facto de se ter de começar de novo. O que é, evidentemente, um paradoxo, dado que a continuidade consiste em: novo projecto, nova promessa de concretização, nova implementação de dívida para com o que há de vir.

5 Lembro-me, por exemplo, da análise de Bojana Bauer (2008) sobre o processo de trabaIho de Até que Deus é Destruído pelo Extremo Exercício da Beleza, de Vera Mantero \& Guests, de 2006.

6 Diz Kunst no citado texto: "We can also reflect upon the project with the help of Gilles Deleuze and his conceptualisation of the difference between virtual and possible: the project can only disclose the possible, it does not belong to the virtual, the possibility is already implemented in it. In that sense, it does not belong to the realm of change." 
Chegada a este ponto e à noção de "dívida”, Kunst justapõe-lhe, num parêntesis, o estado de exaustão como "tonalidade emotiva" (sugestão de tradução de Agamben para as stimmung ${ }^{7}$ haideggerianas), avançando com uma proposta de pensamento da subjectividade assim operante. Diz-nos, então "and this is also the reason for the exhaustion of the subjectivity that works like that": EXAUSTÃO - a temporalidade de projecto em continuidade levaria a um estado de exaustão.

Nessa dimensão temporal de penhora do por vir, e atentando aos processos de subjectivação desencadeados, encontrar-se-ia uma ligação entre o trabalho criativo e os modos produtivos do capitalismo. É que essa perseguição do horizonte último do projecto influenciaria a aceleração do trabalho criativo, requerendo uma contínua e cada vez mais radical individualização do sujeito, que, não obstante e por maior que seja o seu grau de individualização, projecta estandardizadamente, sendo a produção da subjectividade (neste caso da subjectividade que faz projectos) "a mais importante e primária forma de produção, a 'mercadoria' que subjaz à produção de todas as mercadorias", no dizer de Maurizio Lazzarato (apud Kunst, 2012).

Relacionando directamente esta análise com as artes performativas, a autora constata o crescente interesse pelos jovens artistas e a multiplicidade de estruturas que alimentam a sua "emergência" (residências, redes, plataformas de formação, mostras de jovens trabalhos), atentando à sua razão de ser. De facto, analisando-o sob o ponto de vista das dinâmicas contemporâneas de produção, em particular no que diz respeito ao trabalho dos artistas, é interessante verificar que esse interesse deriva não do seu trabalho concretamente, uma vez que este ainda mal começou, mas da "promessa" que as suas jovens práticas encerram: os seus potenciais feitos estão ainda por vir.

O que nos traz de volta ao "e mais um bocadinho", o tal bocadinho que há de vir, aquele que é difícil de enumerar no CV porque ou ainda não aconteceu ou excede a sua descrição: aquele de que tão orgulhosa quanto ironicamente Inês e Diogo nos dão conta no trailer que vimos.

Han Shot First, diz-nos a descrição do Youtube, é um obra sobre o início e a dificuldade do início que - e por isso o invoco hoje aqui - adopta como tom

7 “Maneira fundamental como o ser está, a cada vez, já disposto" (AGAMBEN, 2014, p. 89). 
e como modo uma paródia à celebração. E nisto traz à luz a CELEBRAÇÃO como outra das tonalidades emotivas dessa temporalidade que vimos projectiva: "Tivémos apoio da Direcção Geral das Artes [DGARTES]!', "Fui escolhido para a residência X!', "Tive bolsa de Y!', "Fui aceite em H!', "A proposta foi aceite!', "O apoio saiu!" É de celebrar.

É que o trabalho de todas essas jovens promessas está ainda por vir. Fa-lo-ão em cursos, residências, open studios, mostras, apresentações em prédios cedidos provisoriamente, precários pontos de apresentação onde (com sorte, é de celebrar! - daí o tom comemorativo de cada uma dessas ocasiões) mais um bocadinho do projecto será levado a cabo, apresentado, adquirirá valor de circulação. O que nos diz algo sobre a instabilidade desse seu valor, que continuamente tem de ser testado e mediado, posto em apresentação (o que faz pensar na figura do virtuoso ou do performer como o trabalhador por excelência do pós-fordismo, como sugere Paolo Virno ${ }^{8}$ ).

Kunst especula então sobre o papel dos artistas na contemporânea produção de subjectividades (arrojadas, promissoras, intrépidas) em perpétua condição de "precariedade experimental": forças de trabalho mal pagas ou não pagas de todo, constantemente em fluxo (de residência em residência, projecto em projecto, apresentação em apresentação, país em país), perpetuamente em processo de transformação porque constantemente sujeitos a escrutínio do público, em aprendizagem constante e concorrência feroz.

Para terminar, a autora propõe três pontos que, a seu ver, poderiam contribuir para colocar fora de cena essa "temporalidade projectiva" e abri-la ao presente.

(1) Não à especulação económica sobre o futuro valor da arte (o "promissor"):

Neste ponto, tendo como horizonte a erosão da esfera pública nas sociedades neoliberais e a impotência da arte (por mais politizada que se afirme)

8 Paolo Virno, em A Gramática da Multitude, faz da figura do "virtuoso" - de que o paradigma seria o bailarino, o músico, o orador empolgado... o performer, em suma - aquele cuja actividade se cumpre em si mesma, sem que dela resulte a produção de um objecto exterior, e cuja actividade exige a presença dos outros - um eficaz objecto de análise das mutações pós-fordistas do trabalho. De acordo com o autor, "com o nascimento da Indústria Cultural, o virtuosismo converte-se em trabalho massificado" porque nesta a "actividade comunicativa, que em si mesma se cumpre, é um elemento central e necessário. $O$ trabalho assemelha-se então cada vez mais a uma "execução virtuosa" (VIRNO, 2004, p. 53-55). 
em fugir àquilo a que a crítica "populista" chama "elitismo esquerdista", a autora insurge-se contra uma suposta defesa de que a arte seria boa para a economia e para o mercado, retórica esta que tem minado muita da argumentação sobre os cortes orçamentais na cultura. Assim, seria importante repensar o valor social e político da arte, entendendo-os como intimamente ligados à percepção, reconhecimento e determinação da visibilidade do que temos e poderemos ter em comum.

(2) Sim à apropriação do tempo presente

"Não é muito interessante, bem sabemos, mas é aquilo que temos À MÃO." Relembro aqui a segunda frase para a qual, no início, chamei atenção. Diz a autora: "Sim à persistência no presente, à duração e à endurance. É de uma importância primordial para a arte e para os trabalhadores neste campo exigir continuidade, persistência e ocupar espaços do presente tanto quanto possível. O que é comum é aquilo que é agora e não o que virá” (KUNST, 2012, tradução nossa). Trata-se, portanto, de encontrar formas de reclamar a possibilidade de presente, repensando futuro e passado e reactualizando a um tempo só, presente, futuro e passado, num mesmo reclamar. Como criar formas de permitir ao presente readquirir o seu valor temporal, a complexidade e cumplicidade mútua que o constrói sem cair numa retórica que em tudo lembra o comércio da individualista autoajuda? Por via de que estruturas tal poderia ser feito? Quanto tempo levam a construir? E como se constróem? Como passar da ansiedade e da antecipação para uma posição de presente, não um presente cristalizado, mas um presente em devir, feito de negociações, acordos, conflitos, encontros, negociações sobre o passado e construção presente de um futuro colectivo?

(3) Não à excelência e à conclusão de projectos

Neste terceiro e último ponto a autora propõe a recuperação de diferentes modalidades do quotidiano que na actual economia do tempo se assemelham a luxos: preguiça, lentidão, falta de eficiência, bloqueio, resistência a ser global, perder-se na complexidade das próprias ideias, chegar atrasado, levar tempo, ter reticências quanto a estar e a fazer coisas em todo o lado ao mesmo tempo. Mas isto não como afirmação da suposta "preguiça boémia dos artistas", que desmonta enquanto mito, mas numa espécie de afirmação Bartlebyiana da recusa: "I would prefer not to" (eventualmente um pouco à semelhança das teses agambenianas sobre a inoperatividade). 
Segundo Kunst, a desvalorização da arte faria então parte do interesse capitalista geral de que cada um trabalhe para o seu interesse particular estando os modos do seu fazer estruturados de forma a serem administrado via temporalidade projectiva para que a suas propostas não possam durar no presente nem articular-se com nenhum momento comum.

Mas voltemos então ao espectáculo Han Shot First, o que não é muito interessante, bem sabemos, mas é aquilo que temos À MÃO.

$\mathrm{Na}$ candidatura à DGARTES, usada como material do espectáculo e colocada propositadamente disponível no seu blog, é possível ler:

Han shot first é a primeira criação de dois jovens actores independentes. Desde já convém esclarecer que Han shot first nasceu do desenvolvimento de uma ideia prévia de ambos os criadores, intitulada primeira obra. Devido a circunstâncias de programação do Teatro Taborda e a outras de cariz profissional (Diogo Bento e Inês Vaz foram convidados para trabalhar com outras companhias de teatro [...]), este trabalho foi sendo adiado (e desenvolvido) até, finalmente, ter data de estreia marcada para [...], no Teatro Taborda, integrado no ciclo TRY BETTER, FAIL BETTER, com o título com que agora se apresenta. [...] Ainda que possa parecer irónico, a denominação do ciclo onde este espectáculo surge integrado vem mesmo a calhar. Han shot first fala da tentativa, da falha, de dois anti-heróis e do início de dois criadores que executam a sua passagem ao acto. (BENTO; VAZ, 2010, p. 1)

Como se vê, essa é uma obra (neste caso, uma primeira obra) cujas condições de produção são em tudo semelhantes às enunciadas acima. No blog do espectáculo ${ }^{9}$ constam igualmente uma série de fotos sobre essa primeira vez, esse "feriado nacional" na vida de Diogo e Inês, que, como é natural, celebram.

O que nos traz de volta à questão das tonalidades emotivas características dessa temporalidade de projecto: CELEBRAÇÃO ("Tivémos DGARTES!", "Fui escolhido para a residência X!', "O apoio saiu!") e, como vimos, EXAUSTÃO (por se ter de cumprir tudo o que foi proposto no projecto, por preencher formulários e avaliações e relatórios) seriam então os dois estados que por via dessa cinética projectiva, à vez, ou quem sabe por vezes em simultâneo, nos atravessariam, moldando os nossos movimentos, os nossos corpos, as nossas

9 Disponível em: <http://hanshotfirst2010.blogspot.pt/>. 
emoções, o nosso viver em relação. São essas tonalidades emotivas e as suas conseguintes declinações corporais e relacionais o que gostava de trazer para a conversa. Que essas apareçam por via do diálogo com um espectáculo é algo a que a teoria crítica e a crítica de artes performativas poderia não ser indiferente, encontrando assim linhas e pontos de aproximação que as poderiam, quiçá, fortalecer a ambas - animando-nos (de "anima”, não de animação) a todos.

\section{Referências bibliográficas}

AGAMBEN, G. O aberto: o homem e o animal. Lisboa: Edições 70, 2014.

BAUER, B. The Makings of... Production and Practice of the Self in Choreography: The Case of Vera Mantero and Guests. Performance Research, v. 13, n. 1, p. 15-22, 2008.

BENTO, D.; VAZ, I. Apoio pontual 2010: exposição da candidatura. 2010. Disponível em: <https://drive.google.com/file/d/0Bx7kMusFxbz3ZTU0OTBiYTItZTQ5Yy00ZjE4LWEyN2EtYzhmZTM0OGM2Yzdh/view?ddrp=1\&hl=en\&pli=1\#>. Acesso em: 6 dez. 2016.

KUNST, B. The Project Horizon: On the Temporality of Making. Manifesta Journal, n. 16, 2012. Disponível em: <http://www.manifestajournal.org/issues/regret-and -other-back-pages/project-horizon-temporality-making\#>. Acesso em: 6 dez. 2016.

UNIPOP. Seminário Pensamento Crítico Contemporâneo E Trabalho. 11 out. 2014. Disponível em: <https://www.facebook.com/events/846504478693806/>. Acesso em: 6 dez. 2016.

UNIPOP. Unipop. 4 out. 2011. Disponível em: <http://unipop.webnode.pt/unipop/>. Acesso em: 6 dez. 2016.

VIEIRA, A. B. Sobre fazer projectos e a temporalidade que isso implica: performance, eficácia, resistência e desgaste. In: SEMINÁRIO PENSAMENTO CRÍTICO CONTEMPORÂNEO E TRABALHO, 2014, Lisboa. Anais... Lisboa: Unipop; Revista Imprópria, 2014. Disponível em: <http://www.revistapunkto.com/2015/01/sobre -fazer-projectos-e-temporalidade_27.html>. Acesso em: 6 dez. 2016.

VIRNO, P. The Grammar of the Multitude: for an analysis of contemporary forms of life. Los Angeles: Semiotext(e); Foreing Agents; MIT Press, 2004.

Recebido em 05/10/2016 Aprovado em 31/10/2016

Publicado em 21/12/2016 